\title{
MANFAAT RENDAMAN AIR HANGAT DAN GARAM DALAM MENURUNKAN DERAJAT EDEMA KAKI IBU HAMIL TRIMESTER III
}

\author{
Sawitry, Fitria Hikmatul Ulya, Elisabet Jemsi adepatiloy \\ STIKes Karya Husada Semarang, Jl. Kompol R Soekanto No. 46, Semarang, Telp/Fax : (024)6724581 \\ E-mail: fitria12hikmatul@gmail.com
}

\begin{abstract}
ABSTRAK
Edema kaki terjadi hampir 80\% dari semua kehamilan dan dapat menimbulkan ketidaknyamanan selama kehamilan seperti nyeri, merasa berat, kram pada malam hari, penebalan kulit, dan pigmentasi. Salah satu intervensi non farmakologis untuk mengurangi edema adalah rendaman air hangat dan garam yang merupakan intervensi untuk menghilangkan edema pada ekstremitas bawah selama kehamilan. Menganalisis pengaruh rendaman air hangat dan garam terhadap edema kaki ibu hamil trimester III. Penelitian kuantitatif dengan metode quasy eksperimental one group pre test post test desaign. Sampel penelitian sebanyak 16 ibu hamil Trimester III dengan teknik accidental sampling. Analisis data menggunakan uji Wilcoxon. Terjadi penurunan tingkat edema kaki pada ibu hamil dengan selisih nilai tengah edema kaki sebelum 4,00 dan setelah perlakuan sebesar 0,00 .Uji Wilcoxon menunjukkan $\rho$ value 0,000 . Ada pengaruh rendaman air hangat dan garam terhadap edema kaki ibu hamil trimester III.
\end{abstract}

Kata Kunci : rendaman air hangat dan garam; edema; tungkai bawah ; ibu hamil.

\section{THE EFFECT OF WARM WATER AND SALT IMMERSION IN DECLINING LEG EDEMA OF THIRD TRIMESTER PREGNANT WOMEN}

\begin{abstract}
Edema of the legs occurs in almost $80 \%$ of all pregnancies and can cause discomfort during pregnancy such as pain, feeling heavy, cramps at night, skin thickening, and pigmentation. One of the non-pharmacological interventions to reduce edema is soaking in warm water and salt which is an intervention to relieve edema in the lower extremities during pregnancy. This study was to determine the effect of warm water and salt immersion in declining leg edema of third trimester pregnant women. This quantitative research used quasy experimental method one group pre test post test desaign. The total samples were 16 respondents with purposive sampling and random sampling techniques. Data analysis used the Wilcoxon test. The difference in the mean value of leg edema before 4.00 and after treatment was 0.00 . The Wilcoxon test showed $\rho$ value of 0.000 . There is an effect of warm water and salt immersion on leg edema of third trimester pregnant women.
\end{abstract}

Keywords: warm water and salt soaking; edema; lower limbs; pregnant mother

Jurnal SMART Kebidanan licensed under a Creative Commons Attribution-ShareAlike 4.0 International License. 


\section{LATAR BELAKANG}

Kehamilan merupakan keadaan dimana didalam rahim seorang wanita terdapat embrio atau fetus. Kehamilan dimulai pada saat masa konsepsi hingga lahirnya janin dan lamanya kehamilan dimulai dari ovulasi hingga partus yang diperkirakan sekitar 40 minggu dan tidak melebihi 43 minggu. Kehamilan terbagi dalam tiga trimester, dimana trimester pertama berlansung selama 12 minggu, trimester kedua 15 minggu dan trimester ke tiga 13 minggu. Setiap wanita tentu menginginkan kehamilan yang sehat tanpa gangguan hingga masa bersalin. Setiap ibu hamil beresiko mengalami kematian (Manuaba. 2010).

WHO (World Health Organization) mengatakan bahwa setiap hari di dunia ada kematian 830 ibu. Berdasarkan data hasil Rakerkesnas (Rapat Kerja Kesehatan Nasional) tahun 2019, bahwa di Indonesia setiap hari ada 38 ibu yang meninggal yang diakibatkan oleh penyakit atau komplikasi terkait kehamilan persalinan dan nifas. Sebagian besar kematian tersebut seharusnya bisa dicegah dan diselamatkan. Ibu meninggal disebabkan oleh karena komplikasi kebidanan yang tidak ditangani dengan baik dan tepat waktu. Sekitar $15 \%$ dari kehamilan atau persalinan mengalami komplikasi dan $85 \%$ adalah normal (Putra,Y.,\&Siregar,E.S, 2019). Komplikasi pada kehamilan yang menyebabkan kematian adalah aborsi, infeksi, emboli paru, perdarahan setelah melahirkan, tekanan darah tinggi dan eklamsi, komplikasi langsung dan komplikasi tidak langsung. Sedangkan komplikasi persalinan yang menyebabkan ibu meninggal antara lain perdarahan pasca melahirkan, tekanan darah tinggi, preeklamsi, eklamsi, infeksi, retensio plasenta dan penyakit penyerta lainnya.(Achadi. 2019)

Jumlah ibu hamil di Indonesia pada tahun 2018 tercatat sekitar 5.324.562 jiwa dan jumlah ibu hamil propinsi Jawa Tengah mencapai 590.984 jiwa. Berdasarkan data profil Propinsi Jawa Tengah tahun 2018, jumlah kematian ibu di Kota Semarang pada tahun 2018 sebanyak 19 kasus dari 25.074 kelahiran hidup atau sekitar 75,77 per $100.000 \mathrm{KH}$. Angka kematian Ibu (AKI) mengalami penurunan dari tahun-tahun sebelumnya yaitu 121,5 per $100.000 \mathrm{KH}$ pada tahun 2016, 88 per $100.000 \mathrm{KH}$ pada tahun 2017. (Profil dinkes kota semarang Tahun 2018 )

Kehamilan mengalami perubahan fisiologis dan psikologis. Perubahan fisiologis diantaranya perubahan organ reproduksi, sistem kardiovaskuler, pernapasan, ginjal, integumen, muskuloskeletal, neorologi, pencernaan dan endokrin. Perubahasikologis merupakan respon emosional yang terjadi akibat perubahan organ tubuh dan peningkatan tanggung jawab menghadapi kehamilan dan masa perawatan anak. Perubahan yang terjadi selama kehamilan membutuhkan suatu proses adaptasi, baik fisik maupun psikologis yang mengakibatkan ketidaknyamanan selama kehamilan antara lain mual, muntah, saliva berlebihan, keletihan, nyeri punggung bagian atas, leukorea, peningkatan frekwensi berkemih, nyeri ulu hati, flatulen, nyeri punggung bawah, hiperventilasi, kesemutan dan kaki bengkak (Maternity, Dainty. 2017 ).

Edema pada kehamilan dipicu oleh perubahan hormon ekstrogen sehingga dapat retensi cairan. Peningkatan retensi cairan ini berhubungan dengan perubahan fisik yang terjadi pada kehamilan trimester akhir yaitu semakin membesarnya uterus seiring dengan bertambahnya berat badan janin dan usia kehamilan. Selain itu, peningkatan berat badan akan menambah beban kaki untuk menopang tubuh ibu. Hal ini akan memicu terjadinya gangguan sirkulasi pada pembuluh darah balik dikaki yang berdampak pada munculnya edema.( Lestari, T. W., Nurul, M., \& Admini. 2018)

Edema yang terjadi pada kehamilan umumnya adalah edema kaki Edema kaki ditemukan sekitar $80 \%$ pada ibu hamil trimester III, terjadi akibat dari penekanan uterus yang menghambat aliran balik vena dan tarikan gravitasi menyebabkan retensi cairan yang semakin besar. Edema dapat menjadi gejala awal yang mengarah pada kondisi patologis bahkan sebagai indikator penyakit kronis dalam kehamilan seperti anemia, intrauterine growth restriction(IUGR), preterm labor, tekanan darah tinggi, preeklamsi, eklamsi, solusio plasenta, plasenta previa hidramnion. Beberapa penyakit yang menyebabkan munculnya edema adalah: jantung kronis, gagal ginjal, penyakit sendi, 
kehamilan, asupan garam yang berlebih dan kelelahan fisik ( Lestari dkk, 2017).

Dampak yang akan terjadi bila edema kaki tidak di atasi dapat menimbulkan ketidaknyamanan pada sebagian ibu hamil. Ketidaknyamanan yang sering dirasakan ibu hamil adalah : nyeri pada daerah edema, terasa berat pada daerah edema, kram pada malam hari, pegal, kesemutan, sesak nafas, penebalan kulit, perubahan warna kulit, dan tidak sedap dipandang. Ketidaknyamanan kehamilan trimester III meliputi sering buang air kecil sekitar $50 \%$, keputihan $15 \%$, konstipasi $40 \%$, perut kembung $30 \%$, edema kaki $25 \%$, kram kaki $10 \%$, sakit kepala $20 \%$, striae gravidarum $50 \%$, hemoroid $60 \%$, sesak nafas $60 \%$ dan sakit punggung 70\% ( Admini, dkk.2018).

Penatalaksanaan edema kaki pada ibu hamil tersebut, dengan menggunakan terapi rendam kaki sebagai alternatif non farmakologi dengan menggunakan metode yang lebih mudah dan murah. Rendam kaki dalam air hangat sangat mudah dilakukan oleh semua orang, tidak membutuhkan biaya yang mahal dan tidak memiliki efek samping yang berbahaya. Selain itu terapi rendam air hangat dapat dikombinasikan dengan garam (Sholecah,dkk.2017).

Penelitian Khotimah (2017), menjelaskan bahwa air garam dapat mengalirkan aliran listrik dibandingkan dengan air tawar dan mengurangi unsur air dan garam menjadi ion negatif. Senyawa itu akan masuk kedalam tubuh manusia dari kaki melalui jaringan meridian yang melintasi jaringan kulit kaki. Terapi air hangat dan garam sebagai alternatif dalam mengatasi edema dalam kehamilan dan menghindari komplikasi dari terapi farmakologis (diuretikum) yang jika digunakan secara tidak hati-hati dapat menyebabkan kehilangan volume cairan, hingga mempurburuk perfusi utero plasenta, meningkatkan hemokosentrasi, menimbulkan dehidrasi janin dan menurunkan berat janin. (Khotimah.2015 ) Pada penelitian ini ini menggunakan air dan garam sehingga 2 komponen ini mudah didapat, mudah dilakukan dan terbukti efektif untuk mengurangi oedema pada kaki.
Hasil survey awal di RB Citra insani, didapatkan jumlah ibu hamil tahun 2017 adalah 175 orang, tahun 2018 berjumlah 210 orang ibu hamil dan jumlah ibu hamil pada tahun 2019 bulan Januari sampai November sebanyak 148 orang ibu hamil. Data yang didapatkan dari bulan September sampai November 2019 ditemukan jumlah ibu hamil sebanyak 40 orang dan yang mengalami edema pada trimester III ada 25 ibu hamil. Edema yang terjadi pada ibu hamil tersebut merupakan edema fisiologis. Peneliti juga melakukan wawancara dengan bidan, didapatkan bahwa rata rata pada ibu hamil yang melakukan pemeriksaan pada trimester III, 60\% ibu hamil mengalami edema kaki. Penatalaksaan yang diberikan bidan adalah menyarankan ibu agar tidur kaki lebih tinggi dari kepala, kurangi konsumsi garam yang berlebih, Kurangi duduk dengan kaki menggantung dengan waktu yang lama dan istirahat yang cukup.

Disamping mewawancarai bidan RB Citra Insani pada hari Senin, 9 Desember 2019, peneliti juga melakukan wawancara terhadap 4 orang ibu hamil yang terdiri dari 1 orang G1P0A0, 2 orang G2P1A0, 1 orang G3P2A0 yang berkunjung saat itu dan mengalami oedem kaki pada trimseter III. Semua ibu hamil tersebut dari berbagai latar belakang pekerjaan yang berbeda,ada yang bekerja dikantor dan ada pula yang tidak bekerja. Semua ibu hamil yang diwawancarai merasakan tidak nyaman dengan kondisi yang dialaminya seperti kaki terasa berat, sering merasakan kram dan dan mudah merasakan lelah akibat oedem kaki tersebut. Berdasarkan pengalaman ibu hal yang sering dilakukan dirumah adalah dengan melakukan kaki ditinggikan daripada kepala.

Berdasarkan fenomena di atas, peneliti belum menemukan study kasus terapi edema kaki dengan rendaman air hangat dan garam pada ibu hamil trimester III, oleh karena itu peneliti melakukan penelitian tentang" Pengaruh rendaman air hangat dan garam terhadap edema kaki pada ibu hamil trismester III di RB Citra Insani Semarang tahun 2019" 


\section{METODE}

Jenis penelitian yang digunakan yaitu kuantitatif dengan metode quasy eksperimental one group pre test post test desaign yaitu cara penelitian yang dilakukan pada satu kelompok dengan metode intervensi dan kontrol, yang dilakukan pada satu kelompok saja. Sampel dalam penelitian ini adalah 16 responden ibu hamil dengan kaki oedema di RB Citra Insani Semarang . Pengambilan sampel menggunakan pendekatan yaitu accidental sampling. Penatalaksaan edema tungkai dilakukan dengan merendam kaki hingga batas $10-15 \mathrm{~cm}$ diatas mata kaki dengan air hangat suhu 38-390c dicampurkan garam epsom 5 sdt dan dilakukan rendaman selama 15-20 menit selama 7 hari.

Penelitian ini sudah melalui uji etik dengan nomor ethical clearance 208/KH.KEPK/KT/III/2020. Data penelitian yang telah didapatkan, diolah dan dianalisis menggunakan statistic deskriptif dan disajikan dalam bentuk mean, median, nilai minimum, nilai maksimum, dan standar deviasi. Analisis bivariat menggunakan uji statistic Wilcoxon dengan taraf signifikansi $5 \%$

\section{HASIL}

Analisis univariat pada penelitian ini untuk mengetahui median, Standar deviasi, nilai minimal dan maximal. Sedangkan anlaisis bivariate digunkan untuk menganalisis pengaruh 1 Pengaruh Rendaman Air Hangat Dan Garam Terhadap Edema Kaki Ibu Hamil di PMB Citra Insani Kota Semarang (tabel 1).

\section{Tabel 1 Pengaruh Rendaman Air Hangat Dan Garam Terhadap Edema Kaki Ibu Hamil $(n=16)$}

\begin{tabular}{lccccc}
\hline $\begin{array}{l}\text { Tingkat } \\
\text { edema }\end{array}$ & Median & SD & Min & Max & $\begin{array}{c}\boldsymbol{\rho} \\
\text { value }\end{array}$ \\
\cline { 1 - 5 } Pre tes & 4,00 & $\pm 0,479$ & 3 & 4 & 0,000 \\
Post test & 0,00 & $\pm 0,403$ & 0 & 1 & \\
\cline { 1 - 3 } & & &
\end{tabular}

Sumber: Data Primer, 2020

Tabel 1 menunjukkan bahwa derajat edema ibu hamil sebelum diberikan intervensi rendaman air hangat dan garam pada 16 responden ibu hamil trimester III dengan edema kaki memiliki median 4,00 dengan kategori derajat edema 3 terendah, derajat edema 4 tertinggi dan standar deviasi $\pm 0,479$. Sedangkan derajat edema setelah diberikan intervensi rendaman air hangat dan garam selama 7 hari pada 16 responden ibu hamil trimester III dengan edema kaki memiliki median 0,00 dengan derajat edema 0 paling terendah, derajat edema paling tinggi 1 dan standar deviasi $\pm 0,403$. Hasil Uji wilcoxon didapatkan $\rho$ value $0,000 \leq 0,05$ maka $\mathrm{Ha}$ diterima $\mathrm{HO}$ ditolak, sehingga disimpulkan bahwa ada pengaruh rendaman air hangat dan garam terhadap edema pada ibu hamil trimester III di RB Citra Insani Kota Semarang.

\section{PEMBAHASAN}

Hasil penelitian diperoleh bahwa, rata rata tingkat edema pada ibu hamil sebelum dilakukan tindakan rendaman air hangat dan garam adalah didapatkan derajat edema paling tinggi derajat 4 dan paling rendah derajat 3 . Ibu dengan edema kaki ini sebelumnya mengalami keluhan kram kaki, kesemutan, dan kaki terasa berat. Derajat edema dapat dilihat dari lamanya cekungan untuk bisa kembali seperti semula setelah dilakukan penekanan pada daerah yang edema.

Hasil penelitian tersebut, menurut peneliti dikarenakan penelitian ini mayoritas respondennya adalah ibu hamil dengan usia kehamilan masuk trimester III(> 36 minggu). Edema yang terjadi pada ibu hamil ini karena faktor usia kehamilan. Secara fisiologis edema kaki pada ibu hamil, terjadi karena akibat dari penekanan uterus yang menghambat aliran balik vena dan tarikan gravitasi menyebabkan retensi cairan semakin besar.

Penilaian edema menggunakan pitting edema yaitu dimana derajat I kedalamannya 1-3 $\mathrm{mm}$ dengan waktu kembali 3 detik, derajat II dengan kedalamannya 3-5 mm dengan waktu kembali 5 detik, derajat III kedalamannya 5-7 mm dengan waktu kembali 7 detik, derajat IV kedalamannya $7 \mathrm{~mm}$ dengan waktu kembali 7 detik (Nur Hidayah, R. 2019). Dampak yang ditimbulkan dari edema kaki pada ibu hamil menimbulkan keluhan seperti : kaki terasa berat, kram pada malam hari dan kesemutan. Keluhan yang terjadi pada ibu hamil trimester III, apabila tidak di atasi akan menyebabkan terganggunya fungsi organ tubuh seperti ; jantung, ginjal dan 
berpengaruh terhadap proses persalinan nantinya.

Hasil penelitian ini sejalan dengan teori bahwa edema pada kehamilan dipicu oleh perubahan hormon ekstrogen, sehingga dapat meningkatakan retensi cairan. Peningkatan retensi cairan ini berhubungan dengan perubahan fisik yang terjadi pada kehamilan trimester akhir yaitu semakin membesarnya uterus seiring dengan pertambahan berat badan janin dan usia kehamilan. Selain itu, peningkatan berat badan akan menambah beban kaki untuk menopang tubuh ibu. Hal ini akan memicu terjadinya gangguan sirkulasi pada pembuluh darah balik di kaki yang berdampak pada munculnya edema.( Khotimah. 2015)

Selain itu menurut Putra, Y, Suhendri(2019), edema dapat terjadi pada kehamilan normal. Reaksi yang paling nyata diantara banyak reaksi ibu terhadap hormon kehamilan yang berlebihan adalah peningkatan ukuran berbagai organ organ kehamilan. ( Putra, Y., \& Siregar, E. S. 2019)

Hasil penelitian diperoleh derajat edema pada ibu hamil setelah dilakukan tindakan rendaman air hangat dan garam mengalami perubahan yaitu derajat edema paling tinggi derajat 1 dan paling rendah 0 . Setelah dilakukan rendaman air hangat dan garam ibu merasa sangat nyaman dan ibu tidak lagi merasa kesemutan seperti biasanya.

Hasil penelitian tersebut, menurut peneliti dengan adanya edema kaki pada 16 responden ini, diperlukan tindakan penanganan dengan segera. Salah satu upaya yang dilakukan yaitu dengan melakukan rendaman air hangat dan garam. Pada penelitian ini, penatalaksaan edema tungkai dilakukan dengan merendam kaki hingga batas 10-15 cm diatas mata kaki dengan air hangat suhu 38-390c dicampurkan garam epsom 5 sdt dan dilakukan rendaman selama 1520 menit selama 7 hari.

Hasil penelitian ini sejalan dengan teori bahwa kaki yang direndam air hangat dan garam akan terjadi perpindahan panas dari air hangat ke tubuh sehingga menyebabkan pembuluh darah menjadi lebar dan ketegangan otot menurun maka peredaran darah lancar. Dengan adanya pelebaran pembuluh darah maka aliran darah akan lancar sehingga mudah mendorong darah masuk ke jantung. Keadaan ini menyebababakan aliran darah semakin lancar dan tubuh akan menarik cairan yang berada dalam ekstra seluler sehingga mengurangi edema kaki. ( Damarsanti. 2015)

Hasil penelitian santoso(2015) tentang manfaat dari rendam kaki dengan air hangat yaitu menurunkan tekanan darah pada lansia yang menderita hipertensi. Utami(2015) menjelaskan panas pada fisioterapi dipergunakan untuk meningkatkan aliran darah dengan jalan melebarkan pembuluh darah yang dapat meningkatkan suplai oksigen dan nutrisi pada jaringan. Panas juga meningkatkan elastisitas otot sehingga dapat menguraikan kekakuan otot. (Siti Tyastuti. 2015)

Berdasarkan hasil penelitian diperoleh bahwa ada pengaruh rendaman air hangat dan garam terhadap edema kaki ibu hamil timester III di Klinik Citra Insani Semarang ( $p$ value $=0,000$, $(p$ $\leq 0,005$ ). Secara ilmiah terapi rendam kaki air hangat dan garam ini mempunyai dampak fisiologis bagi tubuh. Pertama berdampak pada pembuluh darah dimana hangatnya air membuat sirkulasi darah menjadi lancar, yang kedua adalah faktor pembebanan didalam air yang menguntungkan otot otot ligamen yang mempengaruhi sendi tubuh. Air hangat yang memiliki dampak fisiologis pada tubuh berupa peningkatan sirkulasi darah dengan memperlebar pembuluh darah sehingga lebih banyak oksigen yang dipasok ke jaringan serta menguatkan otot-otot dan ligamen dan meningkatkan sirkulasi darah kembali ke jantung sehingga mengurangi edema kaki.

Menurut peneliti adanya pengaruh terapi rendaman air hangat dan garam ini terhadap edema tungkai bawah ibu hamil disebabkan karena kaki yang direndam air hangat akan terjadi perpindahan panas dari air hangat ke tubuh sehingga menyebabkan pembuluh darah menjadi lebar dan ketegangan otot menurun maka peredaran darah menjadi lancar. Dengan adanya pelebaran pembuluh darah maka aliran darah akan lancar sehingga mudah mendorong darh masuk ke jantung. Keadaaan ini menyebabkan aliran darah semakin lancar, maka hasil akhirnya sirkulasi darah kembali ke 
jantung sehingga lebih mudah untuk tubuh menarik kembali cairan yang berada dalam ekstra seluler dan akan mengurangi edema kaki.

Perlakuan yang dilakukan pada sore hari ini dimaksudkan agar setelah diberi terapi rendam kaki menjadi lebih rileks pada waktu tidur. Waktu tidur merupakan waktu dimana aktivitas tubuh beristirahat dimana irama jantung, nadi dan aliran darah lebih stabil dan hal tersebut merupakan saat yang tepat bagi penyerapan cairan yang tertimbun diekstravaskuler. Selain itu, posisi berbaring juga baik untuk aliran balik vena dari ektremitas bawah ke jantung. ( saifudin. 2014)

Hasil penelitian ini sejalan dengan penelitian yang dilakukan oleh Ayuro Cumayunaro, 2017 "pengaruh terapi rendaman air hangat terhadap edema tungkai bawah ibu hamil, dari hasil analisa data dengan menggunakan paired sample t-test didapatkan $p$ value 0,000 , sehingga dapat disimpulkan bahwa ada pengaruh terapi rendaman air hangat terhadap edema tungkai bawah ibu hamil. ( Rita Yulifah, H. 2015)

\section{KESIMPULAN DAN SARAN}

Terdapat penurunan derajat edema kaki pada ibu hamil setelah diberikan rendaman air hangat dan garam. Rata-rata sebelum diberikan rendaman air hangat dan garam adalah 4 point dan sesudah diberikan rendaman air hangat dan garam adalah 0 point. Ibu hamil dapat melakukan rendaman air hangat dan garam sebagai salah satu metode non farmakologi untuk mengurangi ketidaknyamanan akibat edema kaki.

\section{REFERENSI}

Achadi, E. (2019) Kematian maternal dan neonatal di indonesia. Rakerkesnas 2019. Tangerang: Kemenkes indonesia

Darmasanti, P. (2018). Pengaruh Rendam Kaki Dengan Air Hangat Terhadap Tingkat Kecemasan Pada Ibu Hamil Trimester III Di Puskesmas Pegandon Kendal. Nurscope.Jurnal Keperawatan Pemikiran IImiah. 4 (1). 1-10
Kementrian Kesehatan Republik Indonesia. Profil Kesehatan Indonesia tahun 2018. Jakarta: Kementrian Kesehatan Republik Indonesia [Diakses tanggal 11 november 2019]. Didapat dari http://www.depkes.go.id/resources/download/pus datin/profil-kesehatan-indonesia/profil-kesehatanIndonesia-2018.pdf

Khotimah. (2015). Pengaruh Rendaman air hangat terhadap edema kaki ibu hamil. JUrnal kebidanan, volume 5,No 1

K.Kartini. (2019). Repo.poltekkes palangkaraya.ac.id

Lestari, T. W., Nurul, M., \& Admini (2018). Penerapan pijat kaki dan rendam iar hangat campuran kencur terhadap edema kaki ibu hamil trimester III di wilayah kerja puskesmas wangon banyumas. Jurnal kebidanan.

Maternity, Dainty. (2017). Asuhan Kebidanan Komunitas. Andi : Yogyakarta.

Manuaba. (2010). Ilmu Kebidanan Penyakit Kandungan.

Agus. (2010). Pengolahan dan Analisis Data Kesehatan KB. Jakarta : EGC

Profil Dinas kesehatan Kota Semarang tahun 2018

Putra, Y., \& Siregar, E. S. (2019). Pengaruh terapi rendam air hangat terhadap edema tungkai bawah ibu hamil. Jurnal Kesehatan, Volume 10 Nomor.2.

Rita Yulifah, H. (2015). Asuhan Kebidanan pada kehamilan Fisiologis. Bandung: Salemba Merdeka.

Saifudin(2014). Buku Panduan Praktiks Pelayanan Kesehatan Maternal. Jakarta : YBPSP

Sholecah, n., Masi, G., \& Rottie, J. (2017). Pengaruh terapi rendam kaki dengan air hangat. ejournal Keperawatan (e-Kp) Volume 5, Nomor 1.

Siti Tyastuti (2015). Modul Asuhan Kebidanan Kehamilan. Jakarta: Depkes

Yanti, M., Purba, T., Ariescha, P. A., Manalu, A., Siagian, N., \&., M. (2020). Pengaruh Penerapan Pijat Dan Rendam Kaki Dengan Air Hangat Campuran Kencur Terhadap Edema Kaki Pada Ibu Hamil. Jurnal Kebidanan Kestra (Jkk), 2(2), 164171.

Yuhendri P., Ega Sharifa S,. (2019). Pengaruh Terapi Rendam Air Hangat Terhadap Edema Tungkai Bawah Ibu Hamil. Jurnal Kesehatan.ejurnal.stikesprimanusantara.ac.id/ind ex.php/JKPN/article/view/407 